\title{
La cuestión generacional en el discurso del gremialismo y la Unión Demócrata Independiente durante la dictadura de Pinochet
}

\author{
Víctor Muñoz Tamayo ${ }^{1}$ \\ Recibido: 25 de mayo de 2018 - Aprobado: 13 de julio de 2018
}

\begin{abstract}
Resumen
El artículo analiza la manera en que el denominado gremialismo, que lideró Jaime Guzmán durante la dictadura de Pinochet, articuló y proyectó determinadas nociones de generación, a través de las cuales promovió su proyecto político y produjo identidad militante. En una primera parte, el texto aborda los conceptos "juventud" y "generación" en tanto producciones ideológicas vinculadas a proyectos políticos, y el modo en que tal fenómeno ha sido abordado por la historiografía y las ciencias sociales en Chile. En la segunda parte se estudia la producción ideológica de juventud y generación que emerge con el Frente Juvenil de Unidad Nacional y que tiene continuidad en el partido Unión Demócrata Independiente, que se presenta a sí mismo como "nueva generación" en política. Se utilizan fuentes bibliográficas y documentales, como revistas de circulación nacional y documentos obtenidos en la Fundación Jaime Guzmán.
\end{abstract}

Palabras clave: generaciones, Unión Demócrata Independiente, gremialismo, dictadura.

The generation issue in the "gremialista" discourse and the Unión Demócrata Independiente during Pinochet's dictatorship
Abstract
The article analyzes the way in which, during Pinochet dictatorship, the so- called "gremialismo" led by Jaime Guzmán articulated and projected certain notions of generation in order to promote his political project and produce

1 Chileno. Doctor en Estudios Latinoamericanos, Universidad Nacional Autónoma de México. Investigador del Centro de Estudios de la Juventud, Universidad Católica Silva Henríquez, Chile. El presente artículo reúne información y análisis producto de dos proyectos ejecutados por su autor y relativos al estudio de generaciones políticas: Fondecyt Postdoctoral $\mathrm{N}^{\circ}$ 3110075 y Fondecyt Iniciación No 11140307. E-mail: vmunozt@ucsh.cl 
militant identity. In the first part, the text addresses concepts of youth and generation as ideological productions linked to political projects, and the way in which this phenomenon has been addressed by historiography and social sciences in Chile. The second part studies the ideological production of youth and generation emerging with the National Unity Youth Front and continuing in the Independent Democratic Union party that introduces itself as a "new generation" in politics. It uses bibliographic and documentary sources such as national journals and documents obtained in Jaime Guzmán Foundation.

Keywords: generations, Independent Democratic Union, unionism, dictatorship.

\section{A questão geracional no discurso do gremialismo e a União Democrata Independente durante a ditadura de Pinochet}

\section{Resumo}

0 artigo analisa a maneira em que o denominado gremialismo que liderou Jaime Guzmán durante a ditadura de Pinochet, articulou e projetou determinadas noções de geração, através das quais promoveu seu projeto político e produziu identidade militante. Em uma primeira parte, o texto aborda os conceitos juventude e geração quanto produções ideológicas vinculadas a projetos políticos, e o modo em que tal fenômeno tem sido abordado pela historiografia e as ciências sociais no Chile. Na segunda parte, estuda-se a produção ideológica de juventude e geração que emerge com o Frente da Juventude de Unidade Nacional e que tem continuidade no partido União Democrata Independente que se apresenta a si mesmo como "nova geração" em política. Utilizam-se fontes bibliográficas e documentais, como revistas de circulação nacional e documentos obtidos na Fundação Jaime Guzmán.

Palavras-chave: Gerações, União Democrata Independente, Gremialismo, Ditadura.

\section{Las nociones de "juventud" y "generación" como producción ideológica e identitaria en política: Problemática histórica y abordajes}

Las categorías etarias de adultez y juventud, y el concepto "generación", han sido referencias recurrentes en las definiciones identitarias de proyectos políticos y militantes, tanto en Chile como a nivel mundial. Basta analizar la historia contemporánea para observar que se ha hecho política desde determinadas concepciones y valoraciones de juventud y adultez, configurando categorías relacionadas que operan proyectando nociones de orden social. Como lo planteara en su momento Pierre Bourdieu (1990), deslindar al joven del adulto supone un ejercicio de poder, es decir, implica leer una realidad estructurada al tiempo que proyectar y estructurar 
realidad social, dos cuestiones que definen los sentidos de lo político. ${ }^{2}$ Pero al mismo tiempo, se ha utilizado cierta carga simbólica en torno a lo adulto y lo juvenil para caracterizar al proyecto político propio, dibujando a los actores y sus contextos según virtudes, defectos, esperanzas, riesgos, posibilidades y amenazas que son asociadas a tipos generales o esenciales de juventud y adultez.

Vista en sus expresiones más nítidas, y a la vez extremas, la construcción social e ideológica de la edad se ha relacionado en política con cierta tensión binaria entre, por una parte, destacar los atributos de renovación o vitalidad de un proyecto asociándolo simbólicamente a la juventud, lo que algunos autores han llamado efebolatría o culto a las virtudes juveniles expresadas en determinadas orientaciones políticas (Brito, 2004); y, por otro lado, valorar y destacar la experiencia de los adultos como voz de prudencia ante ciertas pasiones o riesgos juveniles que son representados como amenaza, en la línea de lo que Duarte (2006) ha estudiado como discursividades "adultocéntricas", que conciben la juventud como tiempo de espera y/o preparación para una inserción plena y en tanto sujeto, que solo se concretaría al momento de la adultez.

Los ejemplos son numerosos en uno u otro sentido. El fascismo italiano se suele destacar como caso paradigmático de culto a lo joven que buscó asociar dicho proyecto político con determinadas "virtudes juveniles": vitalidad, renovación, fortaleza, es decir, el fascismo como juventud inextinguible transferida a una patria fuerte y nunca decadente (Malvano, 1996). Con anterioridad, a inicios del siglo XX en América Latina, los primeros movimientos juveniles y estudiantiles echaron mano de Ariel, la obra de José Enrique Rodó (1920), para plantear que aquellas sociedades que contenían las características propias de la juventud eran las que llevaban a niveles superiores las virtudes humanas, cuestión que derivaba en entender a los actores juveniles como agentes imprescindibles para la renovación y los cambios con sentido progresista (Moraga, 2007; Salazar y Pinto, 2002). Desde esa perspectiva, el orden oligárquico representaba la senectud resistente a una renovación promovida por lo joven.

2 Se entenderá la juventud como una categoría heterogénea, plural ("juventudes") e histórica, que da cuenta de dimensiones sociales, biológicas y vitales que permanecen interrelacionadas y en tensión respecto a la definición de una edad señalada como intermedia entre una niñez y una adultez (también definidas según esos aspectos). Este artículo se centra en el concepto de juventud como construcción social que involucra elementos simbólicos e ideológicos. Sobre la distinción entre la condición juvenil y la estudiantil, es pertinente aclarar que, si bien hay y ha habido juventud más allá de los estudiantes, es claro que durante el siglo XX las representaciones más difundidas de juventud solían estar vinculadas a los sujetos escolarizados y pertenecientes a la juventud universitaria, sobre todo las que referían a la juventud como actor sociopolítico (miradas, por cierto, con evidente sesgo de clase) (Margulis y Urresti, 1996; Toro, 2012; González y Feixa, 2013). 
En un sentido contrario, también ha sido recurrente aquel discurso de temor a lo que se suele describir como elementos caóticos o disruptivos de lo juvenil frente a una idea conservadora de progreso, como se apreció en ciertos discursos de posguerra en los Estados Unidos de la décadas de 1950 y 1960 (Passerini, 1996). Se trataba de la imagen de un joven que, confundido por los cambios que marcarían su tránsito evolutivo a la madurez, era propenso a la evasión irracional o a la búsqueda de refugios afectivos de tipo tribal, como las pandillas. Ese tipo de discurso resistió las representaciones de una juventud rebelde, politizada, actor público propositivo o germen de nueva sociedad deseable y, en cambio, prefirió la imagen del adolescente inadaptado, violento, antisocial, irrespetuoso, carente de normas, e incapacitado para ser agente social pleno. De tal modo, la juventud era vista fundamentalmente como un problema a ser atendido por la sociedad adulta, una población que con urgencia debía ser encauzada, formada y disciplinada.

El siglo XX transitó, entonces, entre dicotómicas representaciones de "misión salvadora" o "fuerza amenazante" en relación a la juventud, imágenes que, en ocasiones, llegaron a coexistir o alternarse de acuerdo a las circunstancias, sus emisores y destinatarios.

En el Chile contemporáneo podemos recordar discursos de culto a la impronta juvenil, como el de los estudiantes antioligarcas que criticaron al parlamentarismo de principios de siglo XX, apelando a las virtudes renovadoras que el ya mencionado Ariel había visto plasmadas de modo esencial en la juventud. Como señaló el poeta mártir de la bohemia estudiantil, José Domingo Gómez Rojas, al referirse a su generación: "Vociferábamos contra los burgueses y inosotros los dioses! como nos llamábamos a nosotros mismos, supimos comprender entonces que nuestra virtud de juventud debía renovar el mundo" (Moraga y Vega, 1997: 14). O la versión chilena del poder joven reformista de los años 60, que Eugenio Tironi definiría luego del golpe de Estado como un "sentido de omnipotencia histórica" presente en la generación juvenil de dicha década: "Fuimos dioses desde siempre. En nosotros, aquel sentimiento de omnipotencia que, para bien de la especie, cada cual lleva consigo, fue llevada hasta el límite (...). No entramos pidiendo permiso: éramos los dueños del país, los más apropiados escultores de su destino; o al menos, así nos sentíamos" (Tironi, 1984: 17). Para Tironi, el poder joven se relacionaba con una generación de la izquierda chilena que asumió tempranamente que la historia estaba a su alcance, y que más tarde viviría el golpe de Estado como una expulsión violenta de esa imagen de poder y agencia histórica.

Del mismo modo, en política también han sido múltiples aquellas producciones ideológicas de la adultez en tanto voz de la experiencia que la juventud debe escuchar, como parte de una formativa, respetuosa y paciente espera de su propio protagonismo. Dicha noción aparece en el recordado 
discurso de Salvador Allende durante 1972 en Guadalajara. En dicho texto se plantea que aquello de "ser joven y no ser revolucionario" podía ser una contradicción hasta biológica, y un vínculo relativamente sencillo para el joven estudiante que todavía no se insertaba como profesional en la sociedad burguesa, pero el revolucionario se asentaba en la adultez y, en último término, los actores protagónicos de la revolución eran los trabajadores y no los jóvenes estudiantes (Muñoz, 2004).

Sobre lo generacional, las identidades políticas que han relevado este concepto han destacado la impronta epocal forjada en quienes vivieron intensamente una juventud bajo determinado contexto. Son claras, por ejemplo, las referencias generacionales de las dirigencias y los intelectuales de izquierda que eran jóvenes durante el golpe de Estado de 1973 y que, a partir de entonces, fundamentarán constantemente sus posicionamientos apelando a los aprendizajes obtenidos durante esos días traumáticos. Indudablemente, muchos discursos de la renovación socialista tienen esa impronta generacional, desde Eugenio Tironi y su citado balance hasta Tomás Moulián y su referencia al 11 de septiembre como "el día que se acabó mi juventud" (Moulián, 1998). Pero en el caso de la izquierda la comprensión fundamentalmente clasista de las luchas sociopolíticas limitó las discursividades que vincularan explícitamente una determinada identidad generacional con un proyecto o conciencia histórica militante. En un sentido diferente la derecha gremialista, tal como desarrollaremos en este artículo, basó su propio relato histórico en una determinada interpretación de la problemática generacional aplicada a su experiencia, un relato que cumplía una función identitaria, pero que también sirvió para generar una imagen propia desde la cual promover su proyecto y protagonismo.

En definitiva, referencias a las edades y a las generaciones han estado presentes en el modo en que se han representado simbólicamente, y se han llenado de sentidos identitarios, las apuestas políticas militantes. En lo que se refiere al estudio de estos fenómenos, el concepto "generación" ha sido utilizado, en general, para dar cuenta de determinada impronta epocal en las subjetividades sociales, o del vínculo entre lo etario y los posicionamientos y discursividades políticas en determinados contextos y trayectorias históricas. En la disciplina histórica esto no siempre se ha hecho en diálogo con las diferentes, y a veces opuestas, tradiciones relativas al concepto "generación", cuyas principales referencias suelen ser, por un lado, Ortega y Gasset, y por otro, Karl Mannheim. Las omisiones o referencias parciales de estos autores pueden aumentar la confusión, pues es muy diferente basarse en uno o en otro, y no resulta preciso totalizar el concepto en uno u otro sentido obviando una cuestión fundamental: no hay un consenso intelectual y académico sobre las implicancias de la categoría "generación". Solo por nombrar las distinciones más notorias, un enfoque basado en el método generacional de 
Ortega (1956 y 1965) o de su discípulo Julián Marías (1967) tendería a validar una duración esencial de las generaciones (15 años de formación y 15 años de gestión); establecería zonas de fechas de 15 años en donde se incluirían los sujetos de acuerdo a sus edades (Fuenzalida, 2003); y consideraría como generaciones de actoría histórica protagónica solo a aquellas compuestas por sujetos mayores de 30 años. En cambio, una mirada con influencias de la sociología de Mannheim (1993) rechazaría las temporalidades determinadas y las totalizaciones en relación a los coetáneos, y se focalizaría en comprender las marcas históricas que se imprimen en las subjetividades de aquellos que, compartiendo edades, van estructurando su conciencia histórica a partir de las socializaciones y experiencias juveniles. Es decir, un enfoque cercano a la mirada del sociólogo húngaro-alemán consideraría tales vivencias de juventud como huellas con un peso específico y determinante en la constante y dialéctica incorporación de nuevas experiencias por parte de los sujetos. Por lo anterior, mientras en una mirada orteguiana el periodo juvenil no resultaría fundamental para la comprensión de las generaciones (pues las generaciones que disputan la construcción de la historia serían adultas), desde una mirada influenciada por la teoría de Mannheim ocurriría lo contrario, ya que se releva a la juventud como periodo en que emerge el sujeto que incorpora conscientemente las tensiones relativas al cambio o la conservación de la sociedad en la que se inserta. Por último, una mirada orteguiana tendería a esencializar la generación sobre la base de una suerte de ritmo predeterminado de la historia y, por lo mismo, a valorarla como categoría central para el estudio de la historia; mientras un enfoque cercano al de Mannheim valoraría la perspectiva generacional como una más entre otras, es decir, con limitaciones, pero útil en el sentido de ser incorporada a análisis integrales y con eje en el desarrollo sociohistórico de los sujetos y sus contextos.

Desde el estudio de las generaciones políticas, pero con acento en la historia social y el análisis de los movimientos sociales, destaca la producción de Gabriel Salazar (1986, 2015, Salazar y Pinto, 2002). Este historiador inició su producción en este tema a partir del análisis de lo que denominó "la generación de la nueva izquierda de 1968" o "generación" rebelde de 1968", y desde ahí ha pasado a analizar otros contextos que abarcan el siglo XIX y XX. En sus textos ocupa el concepto "generación para dar cuenta de determinadas orientaciones históricas de actores políticos en periodos de diversa duración. Sin adherir a la teoría de Ortega y Gasset, sí se refiere al filósofo español y su concepto de "altura de los tiempos" para analizar la percepción de contemporaneidad y lectura de los sujetos respecto de la historia vivenciada y previa (Salazar, 1986). En su análisis, las generaciones se conectan principalmente con aquella percepción y orientación determinada por marcas epocales. Por momentos, y en algunos textos específicos, refiere a generaciones marcadas por su periodo juvenil, mientras en otros menciona generaciones definidas desde vivencias adultas. En algunos, precisamente en 
su último texto sobre la clase política civil (Salazar, 2015), hace estudios de generación según tramos definidos por años de nacimiento, pero en otros textos previos llega a mencionar generaciones de diversa composición etaria que se conectan con periodos de larga duración histórica (Salazar, 2002). Particularmente interesante es el modo en que refiere a "encuentros generacionales" o tensiones entre sujetos que, siendo contemporáneos, pertenecen a diferentes generaciones, que elaboran distintas lecturas de la historia y del rol histórico que les cabe. En el mismo sentido, las generaciones de Salazar mutan en la historia y se producen desde su interrelación. Sin embargo, como no es su afán elaborar una teoría de las generaciones, ni dialogar con los debates conceptuales al respecto, ocurre que una flexibilidad extrema del concepto hace que la categoría pierda cierta consistencia, sobre todo en el vínculo difuso o cambiante entre lo etario y las marcas de época. También ocurre que, por la propia filosofía de la historia del autor, y su particular mirada que dicotomiza entre movimientos sociales y militancias político partidistas, existe cierta tendencia a presentar la juventud como momento de ruptura asociado a la emergencia de perspectivas que valora como sociocráticas, y la adultez, como momento de pérdida de rebeldía, acomodo y homogeneización conservadora en tanto "clase política" aferrada a las estructuras y lógicas de un ordenamiento institucional que sería ilegítimo frente al despliegue de la historicidad social. Lo anterior se acompaña también de cierta totalización de lo que se considera orientaciones, proyectos o comportamientos históricos predominantes, tanto de los grupos etarios como de las trayectorias generacionales. En este último sentido, resulta particularmente discutible el hecho de sugerir que la generación joven activista izquierdista de los años sesenta se definiría fundamentalmente por nociones radicales del poder popular, obviando el peso social que en ella tuvo el allendismo y las posiciones más institucionalistas, por ejemplo, la dirección que dio Carlos Lorca a la Juventud Socialista, o la fuerza de las Juventudes Comunistas en las federaciones universitarias.

En una perspectiva diferente, que enfatiza en la socialización juvenil como huella clave en la conformación de culturas militantes, están los estudios de movimientos o conglomerados de militancia que tienen un particular sello generacional, como el gremialismo y la UDI en la obra de Verónica Valdivia (2006, 2008 a y 2008 b) y el MAPU en los escritos de Cristina Moyano (2009 y 2010). En la obra de Valdivia, lo generacional aparece como marco sociohistórico que sella las motivaciones e identidades de aquel movimiento que logró revitalizar a la derecha, materializar un proyecto constitucional y conducir la revolución neoliberal en Chile. Acá la UDI se analiza como fruto del aprendizaje político de una generación que articuló un imaginario de sí misma, imaginario mediante el cual interpretó su historia y formuló su proyecto: una derecha que, aun cuando entendiera la política como práctica de elite, concibiera una conexión social que la dotara de apoyo popular y 
rompiera con el correlato de clase de la cultura de los tres tercios. Por su parte, Cristina Moyano, en su obra sobre el Movimiento de Acción Popular Unitaria, MAPU, define a tal partido como "generacional", de vida corta e intensa, pero de prolongada sobrevida como cultura política anclada en las redes, prácticas e influencias de sus cuadros. En tal sentido, la generación, o más bien el partido de impronta generacional que sería el MAPU, aparecería como comunidad política que, trascendiendo al partido mismo, construyó un imaginario interpretativo de la historia común, articulando y justificando con ello, prácticas, lógicas y sentidos políticos culturales.

Dentro de esta misma corriente historiográfica, que relaciona cultura militante y generación, sitúo también mis propios estudios en relación al movimiento estudiantil en Chile y México, y a la cultura política UDI gremialista (Muñoz, 2011 y 2016). La idea central de tales trabajos fue problematizar el concepto "generación", en diálogo con la perspectiva de Mannheim y atendiendo a la construcción identitaria y relacional de las unidades generacionales presentes en los movimientos sociopolíticos.

\section{Del "Chile es bandera y juventud" al "una nueva generación para Chile": Los gremialistas, la UDI y el tema generacional}

Durante la década de 1960, el llamado movimiento estudiantil gremialista de la Universidad Católica, liderado por el estudiante de Derecho Jaime Guzmán, realizó un activismo que reaccionó firmemente en contra de otro movimiento que fue su antagonista: el movimiento reformista que, en sintonía con los planteamientos del centro político socialcristiano y la izquierda marxista, reclamó modos de participación universitaria interestamental como parte de un proceso de democratización a converger con un proceso nacional de transformación de las estructuras sociales y económicas (Garretón, 1985). Al contrario de sus antagonistas, los gremialistas no se definieron a sí mismos como actores políticos que actuaban para incidir en grandes transformaciones estructurales, sino que reclamaron el alejamiento de la universidad y del estudiantado de los temas y las prácticas propias de la política y la militancia partidista. Su oposición a la reforma y a los reformistas se basaba, entonces, en un radical rechazo a las formas y articulaciones que la práctica política militante estaba desarrollando en la sociedad chilena. Para ellos, la politización de la universidad y de la sociedad eran vicios que facilitaban el que la política alterara cuestiones que se juzgaban esenciales, como el derecho a propiedad (sujeto a revisión para realizar la reforma agraria); por lo mismo, su activa oposición al gobierno de Frei y al gobierno de Allende no la definían como oposición política, sino que como defensa social de lo estrictamente gremial, que a su juicio se vería amenazado por el accionar del Estado y los políticos. 
Del mismo modo, la simpatía de sus dirigencias por Jorge Alessandri en las elecciones de 1970 la explicaban como cercanía con un independiente que le pondría límites a la política al tiempo que la conduciría por caminos más técnicos que ideológicos (Valdivia, 2008a). De alguna manera, los jóvenes gremialistas apostaban por la conservación de las estructuras, al igual que los partidos de la derecha política, pero sentían, por un lado, que dicha derecha militante había sido débil ante el ímpetu reformista y politizador impulsado por el centro y la izquierda; y, por otro, que las raíces de su malestar eran más profundas que los adversarios políticos del momento, y tenían que ver con el modo sistémico en que se habían vinculado política y sociedad en Chile desde los años 30 (Valdivia, 2008a, 2008b; Moulián, 2002).

Durante 1973 esta crítica profunda al sistema democrático anclado en la Constitución de 1925 llevó a los gremialistas a exigir la renuncia al presidente Allende y llamar a la construcción de una nueva institucionalidad política a partir de la intervención de las Fuerzas Armadas. Un documento emitido en agosto de 1973 era explícito al respecto:

"Cualquiera sea la asignación de responsabilidades que cada sector realice, es un hecho que todos concuerdan en que la tradicional institucionalidad chilena, hoy virtualmente no existe. No procede, por tanto, seguir defendiendo con declaraciones o recriminaciones mutuas algo que, en la práctica, ha muerto (...). Chile necesita volver íntegramente a la democracia, pero sobre la base de crear una nueva institucionalidad (...) Para emprenderla, sólo existe una fuerza organizada idónea que, en virtud de su autoridad moral y de su situación por encima de grupos y partidos, representa una garantía de unidad para todos los chilenos; las Fuerzas Armadas". ${ }^{3}$

En ese marco, no fue de extrañar que, tras el golpe de Estado, una de las primeras acciones de la Junta Militar fue convocar al líder de los gremialistas, el joven de 27 años Jaime Guzmán, a prestar colaboración en tres tareas: participar de la elaboración de un proyecto constitucional, organizar a la juventud y articular la propaganda. El mismo Guzmán explicó esta situación en una carta a su madre fechada el 15 de octubre de 1973: "Personalmente estoy trabajando full-time con el gobierno, manteniendo aparte únicamente mis clases en la Universidad. Colaboro en una comisión destinada a redactar una nueva constitución, y también en la organización de la propaganda y de la juventud, en la Secretaría General de Gobierno" (Guzmán, 2008: 91).

3 "Hacia una nueva institucionalidad a través de la renuncia de Allende", Declaración de Federación de Estudiantes de la Universidad Católica de Chile, FEUC, y Federación de Estudiantes de la Universidad Católica de Valparaíso, FEUC- V, Santiago, 29-VIII-1973, en Archivo Fundación Jaime Guzmán. 
Sobre el tema constitucional, es conocida la participación de Guzmán en la Comisión Ortúzar, destinada a elaborar un primer anteproyecto de Constitución; su rol de principal redactor de la Declaración de Principios del gobierno de 1974, base de los lineamientos constitucionales, y sus principales ideas en el tema, vertidas, por ejemplo, en la revista Realidad publicada por los gremialistas (Cristi, 2000). En relación a la organización de la juventud, Guzmán promovió a cuadros jóvenes del gremialismo en la dirección de la Secretaría Nacional de la Juventud, organismo dependiente de la Secretaría General de Gobierno que conectaba a la dictadura con las organizaciones sociales intervenidas. Y sobre la propaganda, es claro que la pensó y gestionó en directa relación con la promoción de referentes juveniles, es decir, la ejecutó asociando una idea de juventud con un régimen que compartiría sus principales atributos: renovación, vitalidad, fortaleza, cuestiones que, de paso, se asociaban también a los militares y a la patria: "Chile es bandera y juventud" decía uno de los himnos de la dictadura en los años setenta. Al mismo tiempo, y como síntesis virtuosa, se remarcaba en los jóvenes una cualidad generacional que compartirían con el gobierno: no estaban contaminados con la politiquería del pasado (Muñoz, 2014; González, 2015).

Hacia 1975, el régimen de Pinochet contaba con el respaldo crucial de una red política organizada al interior del propio gobierno y con fuerte presencia en las organizaciones sociales intervenidas de la juventud, como centros de alumnos y federaciones cuyo origen no era democrático sino designado por las autoridades delegadas (Valdivia, 2006; Hunneus, 2000; Muñoz, 2016). Dicha red era dirigida por Jaime Guzmán, que operaba como asesor directo de Pinochet y la Junta de Gobierno. Entonces, la red no formalizada, pero de facto, de los gremialistas, aglutinaba y coordinaba a cuadros que adscribían a aquella lectura política que consideraba que la obra fundamental del gobierno debía abarcar dos grandes transformaciones: un cambio institucional (nueva Constitución, que sentara las bases de una democracia autoritaria, con pluralismo limitado y enclaves de poder de las fuerzas armadas) y nuevo modelo de desarrollo (que concibiera al Estado como ente subsidiario respecto del mercado, en donde radicaría el motor del desarrollo al modo de la ortodoxia librecambista de la escuela económica de Chicago) (Cristi, 2000; Hunneus, 1998; Gárate, 2012). A decir de Carlos Hunneus, esa red era en la práctica un partido político no formalizado, y por el modo, casi sin contrapeso, en que operaba durante la segunda mitad de los años setenta, se habría constituido como equivalente a un partido oficial o partido único del régimen (Hunneus, 2000).

Durante 1975, en lo que sería un ejercicio de organización y movilización juvenil en apoyo al régimen, a la vez que una acción propagandística, desde la Secretaría Nacional de la Juventud se creó el Frente Juvenil de Unidad 
Nacional, FJUN. El FJUN se definía como un organismo de movilización en favor del régimen, que convocaba a militantes, pero que negaba su carácter político, es decir, asumía que su oficialismo sería fundamentalmente una actitud patriótica de unidad nacional ante los ataques del "marxismo internacional" y de los países democráticos de occidente que ("ingenuamente", se decía) condenaban políticamente al gobierno de Chile, fundamentalmente por las violaciones sistemáticas a los derechos humanos. Aquel año el FJUN marcó su inicio con un acto de masas en el "día de la juventud", conmemoración de la Batalla de la Concepción (Guerra del Pacífico, 9 y 10 de julio de 1882), hito histórico en el que murieron 77 militares, varios de ellos de edad adolescente. Aquel acto de 1975 en el cerro Chacarillas sería el primero de varios, siendo el más recordado el del año 1977 en el que Pinochet dio a conocer un primer itinerario hacia una nueva institucionalidad. En las ceremonias nocturnas de Chacarillas se entonaban cantos y emitían mensajes que enaltecían a la juventud y vinculaban sus atributos con los de la patria, los militares y el gobierno: "Tenemos algo nuestro y muy grande por hacer, hoy somos responsables de la patria y su sentir, alegremente serios y sirviendo un ideal, la juventud avanza, no se puede detener", decía el propio himno del Frente Juvenil (Boletín Secretaría Nacional de la Juventud, VI-1977). Los discursos de Pinochet y de los dirigentes juveniles incorporaban, además, una idea recurrente e inseparable del enaltecimiento de las nuevas generaciones: el régimen era joven, porque al igual que la juventud, no estaría contaminado con la "politiquería" del pasado. En esa línea estuvo el discurso de Pinochet al instaurar el día nacional de la juventud:

"Cuando hay políticos que salen a la palestra, salen a hablar y a proponer ideas que no hicieron cuando tuvieron la oportunidad de hacerlo (...) a ellos les digo: Ustedes se acabaron señores; ustedes no son el futuro de Chile. Si quieren saber dónde están los futuros gobernantes de Chile, miren a la juventud, ahí están los nuevos gobernantes. Y eso se los digo no por halagarlos. Sino porque la juventud no está contaminada como lo han estado los políticos" (Boletín Secretaría Nacional de la Juventud, VI-1975).

El mismo contenido expuso más tarde Javier Leturia, presidente del Frente Juvenil de Unidad Nacional, en el marco de su discurso del día nacional de la juventud:

"Nos dirigimos a los políticos chilenos del pasado, para decirles justamente eso: que pertenecen al pasado. Algunos cumplieron su misión con alguna dignidad y un decoro que el país siempre sabrá reconocer. Otros, que corrompieron al país con sus doctrinas foráneas, su politiquería y su blandura demagógica, serán juzgados como se merecen por la historia. Pero unos y otros deben entender que su misión ya terminó, y que la juventud está ahora construyendo el 
futuro que legítimamente le pertenece" (Boletín Secretaría Nacional de la Juventud, VIII-1975).

Los gremialistas asumieron identitariamente dicha relación y se describieron a sí mismos como "los jóvenes del gobierno", cuestión que no era tan alejada de la realidad si se considera que buena parte de los cuadros civiles más relevantes del régimen no venían de la vieja derecha, las antiguas dirigencias del Partido Nacional no estaban en la primera plana gubernamental, sino de las redes gremialistas de Guzmán, ya sea como Chicagos Boys en el equipo económico (el caso del también gremialista Miguel Kast en la Oficina de Planificación Nacional, ODEPLAN), o como organizadores del nuevo proyecto institucional (como el propio Guzmán en la Comisión Ortúzar, o Juan Antonio Coloma como miembro del Consejo de Estado), que eran convocados a participar cuando sus edades fluctuaban entre los veinte y treinta años de edad, y venían de ser líderes estudiantiles gremialistas. La revista Qué Pasa (también controlada por los gremialistas) llamó a esta situación la "Iolocracia" o el "gobierno de los jóvenes" (Qué Pasa, 9-XII-1976), colaborando de esa forma con una imagen que servía a los intereses del gremialismo, pues la relación que evidentemente se estaba promoviendo era aquella que indicaba que si el gobierno podía ser percibido como joven, con todos los atributos que ello implicaba, era justamente por el rol activo de los gremialistas en él.

La promulgación de la Constitución en 1980 y las reformas de corte neoliberal que en esos años irrumpieron en áreas como la educación, la salud y el sistema de pensiones, fueron leídas por los gremialistas como un triunfo de sus posiciones al interior del gobierno. Sin embargo, hacia 1982 y 1983 la inicial euforia y exitismo comenzó a dar lugar a incertidumbre y preocupación ante la crisis económica, la protesta social y la mayor organización y visibilidad de la oposición (Valdivia, 2008b; Rubio, 2013; Muñoz, 2016). Para entonces, las señales del contexto indicaban que se habían acabado los tiempos en que los hombres de Guzmán operaban como el grupo organizado más influyente de la dictadura, pues aunque conservaron espacios de poder (por ejemplo, un número importante de los principales municipios permanecieron con alcaldías designadas gremialistas), el primer lustro de los años ochenta es el momento en que salen de la primera línea del poder gubernamental, al perder terreno en el equipo económico y en el equipo político. Para peor, la emergencia de la oposición social afectó los valorados vínculos que el gremialismo tenía con la representación designada de las organizaciones intervenidas. En el caso específico de los actores jóvenes, el FJUN se disolvió, se terminaron los actos masivos del "Día Nacional de la Juventud" y la Secretaría Nacional de la Juventud dejó de tener el protagonismo de antes, mientras que, en lo estudiantil, la organización de la oposición tomó con éxito las banderas de la democratización de los centros de alumnos y federaciones (García, Isla y Toro, 2006; Muñoz, 2011). 
Como una reacción a las nuevas dificultades, hacia 1983, en un contexto de relativa apertura forzada por la crisis económica y social, y en concordancia con los caminos de la transición a una democracia según los lineamientos de la naciente Constitución, la red gremialista anunció su conformación como movimiento político, creándose la llamada Unión Demócrata Independiente, UDI. A los hombres de Guzmán, ahora UDI, les preocupaba que la crisis derivara en alimentar corrientes "duras" que tendieran a perpetuar al régimen con todas sus características, sin alteración, favoreciendo el inmovilismo frente a los inminentes caminos de la transición. O, por el contrario, que se desatara una aceleración en el tránsito a una democracia plural, precipitando la salida de Pinochet, desechando la Constitución (incluso la oposición más moderada exigió en su momento una asamblea constituyente para una nueva Constitución, negando la promulgada en 1980), o materializando reformas constitucionales que afectaran contenidos considerados imprescindibles para una "democracia protegida", como el pluralismo limitado (el artículo octavo prohibía a la izquierda marxista), el estatus de las fuerzas armadas como garantes de la institucionalidad y los enclaves de autoridad previstos en el diseño institucional como "factores de estabilidad" (acá caben los "correctivos" al sufragio universal, como la institucionalización de senadores designados).

La UDI declaraba convocar a los independientes, ya fuese porque habían optado por no militar en los partidos existentes antes de 1973, compartiendo la crítica que se les hacía en el sentido de haber tolerado el crecimiento del marxismo y la proliferación de reformas que revisaban el derecho de propiedad, o porque hubiesen socializado posteriormente a la crisis de esa democracia, es decir, por ser jóvenes. Con ello, se daba continuidad a la idea de protagonismo juvenil renovador y se reclamaba para el propio referente el carácter de ser una militancia para los jóvenes, como lo señalaron en una inserción en la prensa en la que daban a conocer sus propósitos y principios fundamentales:

"Unión Demócrata Independiente abrirá sus puertas y extenderá su acción proselitista a los diversos sectores del país, pero aspira a contribuir a canalizar principalmente el aporte de vastos conglomerados que no tuvieron militancia partidista hasta 1973, sea porque se mantuvieron como independientes o bien porque integran nuevas generaciones jóvenes que se han incorporado a la vida ciudadana con posterioridad a dicha fecha. Unión Demócrata Independiente desea contribuir así a la indispensable renovación que requiere nuestra vida política" (EI Mercurio, 25-IX-1983).

Sin embargo, vale la pena plantear la pregunta ¿eran jóvenes los líderes fundadores de la UDI? Hacia 1983 Jaime Guzmán parecía alejarse del rango etario joven con sus 37 años, pero Patricio Melero, Juan Antonio Coloma 
y Andrés Chadwick rondaban los 27, y Pablo Longueira recién alcanzaba los 25. Sin embargo, durante la década de 1980 los textos del gremialismo planteaban que emergía una juventud diferente de aquella de la segunda mitad de los setenta, que no había sido socializada en un contexto de promoción de un boom económico, sino de crisis, y que no había sido testigo del intenso activismo oficialista del FJUN, es decir, una generación posterior a la de los principales líderes gremialistas. En 1982, un año antes de la fundación de la UDI, Guzmán escribió al respecto en un artículo titulado "El sentido de la transición" y publicado en revista Realidad, advirtiendo que uno de los desafíos más importantes y difíciles de la obra gubernamental sería "renovarse para interpretar a las nuevas generaciones juveniles" (Realidad, VII-1982). A juicio del líder gremialista, a diez años del golpe de Estado, había jóvenes chilenos que solo habían internalizado recuerdos del régimen militar y no de los gobiernos anteriores. Habría, por lo tanto, una suerte de corte generacional que separaba, por un lado, a los que habían vivenciado el gobierno de la Unidad Popular como jóvenes o desde "las percepciones simples, pero emotivas de la adolescencia", y, por otro, a quienes percibían al gobierno de Allende como el lejano marco temporal de la niñez. A juicio de Guzmán, esa diferencia generacional sería clave, y debía ser asumida por el gobierno y sus actores, pues no se podía interpelar de igual modo a personas con vivencias históricas diferentes. Para el autor, lo anterior incidía en que los jóvenes de 1982 creyeran "normales" o "permanentes" algunos valores y realidades de aquel presente, que a su entender eran realidades recientemente conquistadas por el gobierno ("la paz, el orden y el respeto a las jerarquías"). Lo anterior también incidiría en que los jóvenes de aquella novísima generación no estuvieran en condiciones de comprender cabalmente las "necesidades de restricciones políticas" que el régimen imponía, argumentando que ellas serían necesarias para proteger justamente dichos valores y realidades conquistadas. Aquí Guzmán advierte que el problema de una brecha generacional resulta complejo, pues tampoco bastaría con relatar el pasado del allendismo, o educar en relación a los peligros de un retroceso, ya que: "la experiencia ajena deja forzosamente una huella bastante limitada en quienes no han participado de sus vibraciones gratas o amargas". Pero, para Guzmán, esta imposibilidad de trasladar la vivencia propia de la historia a un tercero generacionalmente menor, lejos de producir desazón, debía motivar en el sentido de asumir que la única posibilidad de sumar a los jóvenes a un respaldo identitario con la obra gubernamental no era enfocar el mensaje en el pasado, sino en el futuro, en el sentido de hacerlos parte de él e invitarlos a plasmar en la realidad (que era fruto de la obra pinochetista) los impulsos renovadores que les serían propios en tanto jóvenes.

En 1986 los gremialistas vuelven a plantear una reflexión sobre el tema generacional, y esta vez lo hacen en un documento partidario, Chile Ahora, que define las posiciones de la UDI ante la contingencia. Dicho texto insistía 
en las mismas ideas fuerza que Guzmán desarrolló en 1982, pero agregando en el análisis el contexto de visibilidad opositora y los éxitos de esta oposición en la movilización de jóvenes. En este punto, se enfatiza en que una brecha generacional marcada por la vivencia y no vivencia de la Unidad Popular, sería aprovechada por la oposición al gobierno para seducir a una juventud a la que no le provocaría el mismo grado de incertidumbre o temor la amenaza de un retorno a un predominio de la izquierda. En el texto se plantea que tal labor "desquiciadora" de la oposición (y de elementos "eclesiásticos") se beneficiaría, además, por el hecho de que dicha juventud habría sido socializada como tal con posterioridad a los años de la "mística" movilización juvenil promovida por la Secretaría Nacional de la Juventud y el FJUN, y justo en el momento en que los diagnósticos optimistas del gobierno respecto a su apoyo, su consolidación institucional y su éxito económico (fundamentados en la promovida idea de que se vivía un boom económico) daban paso a dificultades en lo social, económico y político.

"Existe una brecha generacional alrededor de los 25 años de edad, ya que los jóvenes menores de ella no vivieron la Unidad Popular, ni tampoco los años de éxito, mística y apoyo mayoritario que tuvo el actual gobierno que culminaron en el plebiscito de 1980. Sobre esa generación influye con especial fuerza la acción desquiciadora de los elementos políticos y eclesiásticos más radicalizados. Pero también contribuye a su escepticismo, la falta de un proyecto histórico gubernativo que les resulte atrayente desde una óptica de futuro. Cuando el gobierno insiste en acudir a la justificación de su origen en 1973 como su argumento predominante, esas generaciones más jóvenes lo perciben ajeno y anclado históricamente. Más aún, enrostrarle a esa juventud que sus juicios y acciones provienen de no haber conocido la Unidad Popular, es estéril y hasta contraproducente. Las experiencias se viven o no se viven, pero nunca se transmiten como tales, sino como crónica o historia. Ninguna generación ha aceptado jamás definirse en función de realidades que sólo conoce por vía del relato. Sólo un régimen que hoy se revalide con sentido creador hacia el porvenir puede concitar un respaldo amplio en esas nuevas generaciones" (Unión Demócrata Independiente, 1986: 23).

De este modo, el concepto "generación" fue considerado central para los diagnósticos y las proyecciones políticas de los UDI - gremialistas, y fue adoptado como una herramienta recurrente para interpretar el valor y las fortalezas del proyecto propio. Por lo anterior, durante toda la dictadura Guzmán y sus seguidores siempre destacaron el involucramiento del gobierno con la juventud y las nuevas generaciones cuando eran ellos, como red militante de facto, los que tenían un protagonismo indiscutido en las altas esferas de decisión, es decir, entre 1973 y 1980. Por el contrario, siempre 
diagnosticaron desafección juvenil frente al gobierno y posiciones erradas del poder ejecutivo respecto de las nuevas generaciones cuando consideraron que su sector contaba con un limitado acceso a La Moneda entre 1982 y 1986. Insistieron, por lo mismo, en la siguiente relación: cuando hay nitidez del proyecto futuro y vitalidad en su implementación, hay movilización juvenil e integración generacional; $y$, al revés, cuando hay estancamiento del proyecto emerge una brecha generacional y un "envejecimiento" del apoyo al régimen. Ligado a lo anterior, la propia red gremialista y la UDI se presentaron a sí mismas como garantía y síntesis de la "vitalidad juvenil", que debía expresar el proyecto gubernamental para generar aceptación, identificación y compromiso en las nuevas generaciones.

Este tipo de discurso y enfoque perduró en la UDI. Incluso ya al inicio de los años noventa, en democracia, el boletín del partido llegó a tener por nombre Nueva Generación, y entonces la propia UDI se promocionó con el lema "Una Nueva Generación Para Chile". El concepto "generación" quedaba así como noción enraizada en la cultura política UDI, un término eje para la producción, promoción e internalización de su propia identidad partidaria.

\section{Conclusiones}

Se considera importante recalcar tres elementos del análisis. Primero, que la red gremialista que conformó la UDI venía de promover su propuesta política desde la proyección de una atmósfera ideológica de efebolatría que caracterizó al régimen en toda su primera etapa. Segundo, que en la fundación de la UDI se describió el proyecto de partido como fruto de una generación que, desde su experiencia juvenil, leyó su rol y sentido histórico a partir de las huellas que en su socialización política dejaron la Unidad Popular, el golpe de Estado y el rol formador de su líder Jaime Guzmán. Tercero, que después de la crisis económica de 1982 y la irrupción de las jornadas de protestas antigubernamentales en 1983, la UDI promovió la idea de que su referente seguía representando una impronta juvenil, la que solo era factible de traspasar al régimen si éste articulaba un mensaje de futuro de acuerdo a las orientaciones que la propia UDI proponía. En definitiva, desde lo generacional se leyó la realidad política, desde lo generacional se articuló la identidad propia, desde lo generacional se hizo propaganda política y desde lo generacional se promovió al referente propio como garantía de vitalidad, renovación y juventud.

Por lo mismo, no ha sido casualidad que la palabra "generación" estuviera tan presente en los documentos de cada orgánica creada por Guzmán desde el FJUN hasta la UDI. Como vimos, durante la dictadura hubo, por parte de los gremialistas y la UDI, un análisis permanente sobre la 
importancia de que el régimen considerase la incorporación simbólica de la juventud y las nuevas generaciones, interpelándolas desde un mensaje que enfatizara en dicha incorporación. De tal manera, durante la posdictadura el concepto "generación" quedó instalado en la cultura política, por lo que sigue influyendo en la comprensión del rol de los líderes fundadores de la UDI (o "coroneles", como los llamó la prensa) y de los cuadros socializados con posterioridad al asesinato de Jaime Guzmán, es decir, está al centro del debate sobre la reproducción de las relaciones de poder y mando al interior del partido (Muñoz, 2016).

En un plano más general y relativo a la disciplina histórica, es importante destacar que el potenciar enfoques generacionales en relación al estudio de las militancias políticas permitiría a la historiografía imbricar historia social e historia política en función de producir conocimiento integral de los fenómenos y actores sociopolíticos (entiéndase movimientos sociales y militancias, insertas o no en el sistema de partidos). Por una parte, tomaría de la historia social su foco en los sujetos y los aspectos materiales e identitarios que configuran sus prácticas arraigadas sociohistóricamente, en este caso, el foco en edad y socialización al interior de las militancias sociopolíticas. Por otra, facilitaría también la tarea de desbordar la comprensión de la política como dimensión restringida a las instituciones y su vínculo con el Estado (límite con que se solía estigmatizar a los enfoques de historia política), y enfocarse en el abordaje de las conexiones entre sociedad y política, lo que incluye, por cierto, relacionar el estudio de los movimientos sociales con el de las militancias. De todos modos, un enfoque de este tipo supone asumir las militancias políticas como expresión de comunidades que interactúan con la sociedad y participan de un campo político que es fruto del propio devenir histórico. Es decir, significa asumir que del mismo modo que socialmente se definen las edades y se desarrollan procesos de identificación generacional, se definen también socialmente, de modo conflictivo y polisémico, los sentidos y el campo de la política y sus conexiones sociales. Por lo mismo, creo que un enfoque generacional puede resultar útil si es fruto de una constante problematización en función de conocer la complejidad abordada, eludiendo la tendencia a la recurrente totalización en el acto de nombrar generaciones, tendencia que suele ir acompañada de la esencialización de los movimientos sociales, de las militancias políticas, de los sistemas políticos y, en definitiva, de los vínculos entre política y sociedad. Como podemos aprender de Karl Mannheim, la categoría "generación" pueden ser un terreno fértil si se la asume no como llave maestra totalizadora y explicativa de esencias, sino como una entre otras herramientas teóricas para entender realidades complejas, una herramienta que se crea desde la problematización, que se resiste a la única definición, pero que exige coherencia y tratamiento teórico para ayudarnos efectivamente a la construcción de conocimiento. 


\title{
Referencias bibliográficas
}

\section{Fuentes primarias}

\author{
a) Archivos
}

Archivo Fundación Jaime Guzmán, Santiago.

b) Impresos y documentos

"Hacia una nueva institucionalidad a través de la renuncia de Allende", Declaración de Federación de Estudiantes de la Universidad Católica de Chile, FEUC, y Federación de Estudiantes de la Universidad Católica de Valparaíso, FEUC-V, Santiago, 29-VIII-1973. Archivo Fundación Jaime Guzmán.

Unión Demócrata Independiente (Julio 1986). Chile, Ahora. Santiago: Talleres Printer.

\section{c) Publicaciones periódicas}

Boletín Secretaría Nacional de la Juventud, Santiago, 1975-1978.

El Mercurio, Santiago, 1973-1990.

Qué Pasa, Santiago, 1974-1990.

Realidad, Santiago, 1979-1983.

\section{Fuentes secundarias}

a) Artículos de libros y revistas

Bourdieu, P. (1990). "La juventud no es más que una palabra", en Sociología y Cultura. México: Grijalbo, pp. 163-173.

Brito Lemus, R. (2004). "Cambio generacional y participación juvenil durante el cardenismo", en Urteaga, Pérez Isla, coordinadores, Historia de los jóvenes en México. México DF. IMJ. Archivo General de la Nación, pp. 233-280.

Duarte, C. (2006). "¿Juventud o Juventudes? Versiones, trampas, pistas y ejes para acercarnos progresivamente a los mundos juveniles", en Discursos de resistencias juveniles en sociedades adultocéntricas. San José de Costa Rica: DEl, pp. 113-143.

Fuenzalida, E. (2003). "Generaciones y cultura política en Chile" en Perspectivas en política, economía y gestión. Volumen 6, № 2, Santiago, pp. 219-231. 
González, Y. (2015). "El golpe generacional y la Secretaría Nacional de la Juventud: Purga, disciplinamiento y resocialización de las identidades juveniles bajo Pinochet (1973-1980)", en Atenea, № 512. Concepción: Universidad de Concepción, pp. 87-111.

Hunneus, C. (1998) "Tecnócratas y políticos en un régimen autoritario. Los 'ODEPLAN Boys' y los 'Gremialistas' en el Chile de Pinochet", en Revista Ciencia Política, Volumen XIX, pp. 125-158.

Malvano, L. (1996). "El mito de la juventud a través de la imagen: El fascismo italiano", en G. Levi y J.-C. Schmitt, Historia de los jóvenes. Tomo 2. Madrid: Ed. Taurus, pp. 313-346.

Mannheim, K. "El problema de las generaciones", en Revista Española de Investigaciones sociológicas, № 62. Madrid, pp. 193-242.

Margulis, M. y M. Urresti (1996). "La juventud es más que una palabra", en M. Margulis, La juventud es más que una palabra. Ensayos sobre cultura y juventud, Buenos Aires, Editorial Biblos, pp. 13-30.

Muñoz Tamayo, V. (2004) "Imágenes y estudios cuantitativos en la construcción social de "la juventud» chilena. Un acercamiento histórico (2003-1967)", en Revista Última Década, № 20. Valparaíso: CIDPA, pp. 71-94.

Muñoz Tamayo, V. (2014) "Chile es bandera y juventud". Efebolatría y gremialismo durante la primera etapa de la dictadura de Pinochet (1973-1979)", en Historia Crítica, № 54. Colombia: Universidad de los Andes, pp. 195-219.

Passerini, L. (1996). "La juventud, metáfora del cambio social (dos debates sobre los jóvenes en la Italia Fascista y en los Estados Unidos de América durante los 50)", en Historia de los jóvenes. Tomo 2. Madrid: Ed. Taurus, pp. 383-453.

Salazar, G. (1986). "De la generación chilena del '68: ¿omnipotencia, anomia, movimiento social?", en Proposiciones, № 12. Santiago: Sur, pp. 96-118.

Tironi, E. (1984). "Solo ayer éramos dioses", en La torre de Babel. Ensayos de crítica y renovación política. Santiago: Sur, pp. 17-25.

Toro, P. (2012). "Desórdenes y juegos de chapas en la plaza: estudiantes, espacio público y juventud (San Fernando, c. 1870-c. 1900)", en Historia, № 45, Vol. II. Santiago: Instituto de Historia, Pontifica Universidad Católica de Chile, pp. 485-502.

Valdivia, V. (2006). "Lecciones de una revolución: Jaime Guzmán y los gremialistas, 1973-1980", en Valdivia, V., R. Álvarez y J. Pinto, Su revolución contra nuestra revolución. Vol I. Santiago: Lom, pp. 49-100.

Valdivia, V. (2008b). "Los guerreros de la política. La Unión Demócrata Independiente, 1983-1988" en en Valdivia, V., R. Álvarez y J. Pinto, Su revolución contra nuestra revolución. Vol. II. Santiago: Lom, pp. 139-180. 


\section{b) Libros}

Cristi, R. (2000). El pensamiento político de Jaime Guzmán. Autoridad y Libertad. Santiago: Lom.

Gárate C., M. (2012) La revolución capitalista de Chile (1973-2003). Santiago: Ediciones Universidad Alberto Hurtado.

García, D., J. Isla y P. Toro (2006). Los muchachos de antes. Historia de la FECH 1973-1988. Santiago: Universidad Alberto Hurtado.

Garretón, M. A. y J. Martínez (1985). La reforma en la Universidad Católica. Tomo II. Biblioteca del movimiento estudiantil. Santiago: Sur Profesionales.

Guzmán E., J. (2008). Escritos personales. Santiago: Fundación Jaime Guzmán.

González, Y. y C. Feixa (2013). La construcción histórica de la juventud en América Latina. Bohemios, rockanroleros y revolucionarios. Santiago: Cuarto Propio.

Hunneus, C. (2000). El régimen de Pinochet. Santiago: Editorial Sudamericana.

Marías, J. (1967). El método histórico de las generaciones. Madrid: Revista de Occidente.

Moraga, F. (2007). Muchachos casi silvestres. Historia de le FECH. Santiago: Universidad de Chile.

Moraga, F. y C. Vega (1997). José Domingo Gómez Rojas: Vida y obra. Punta Arenas: Editorial Ateli.

Moulián, T. (2002). Chile actual. Anatomía de un mito. Santiago: Lom.

Moulián, T. (1998). Conversación Interrumpida con Allende. Santiago: Lom.

Moyano, C. (2009). MAPU o la seducción del poder y la juventud. Santiago: Ediciones Universidad Alberto Hurtado.

Moyano, C. (2010). EI MAPU en dictadura. Santiago: Ediciones Universidad Alberto Hurtado.

Muñoz Tamayo, V. (2011) Generaciones. Juventud universitaria e izquierdas políticas en Chile y México. (Universidad de Chile-UNAM 1984-2006). Santiago: Lom.

Muñoz Tamayo, V. (2016). Historia de la UDI. Generaciones e historia política 1973-2013. Santiago: Universidad Alberto Hurtado.

Ortega y Gasset, J. (1956). El tema de nuestro tiempo. Madrid: Ediciones Revista de Occidente.

Ortega y Gasset, J. (1965). En torno a Galileo. Madrid: Espasa Calpe.

Rodó, J. E. (1920). Ariel. Valencia: Editorial Cervantes. 
Rubio Apiolaza, P. (2013). Los civiles de Pinochet. La derecha en el régimen militar chileno, 1983-1990. Santiago: DIBAM.

Salazar, G. y J. Pinto (2002) Historia Contemporánea de Chile V. Niñez y Juventud. Santiago: Lom.

Salazar, G. (2015). La enervante levedad histórica de la clase política civil. Santiago: Penguin Random House.

Valdivia, V. (2008a). Nacionales y Gremialistas. El parto de la nueva derecha política chilena, 1964-1973. Santiago: Lom.

\section{Cómo citar este artículo:}

Muñoz Tamayo, V. (2018) "La cuestión generacional en el discurso del gremialismo y la Unión Demócrata Independiente durante la dictadura de Pinochet", en Revista de Historia y Geografía, N³9, pp. 99-119, Escuela de Educación en Historia y Geografía, Universidad Católica Silva Henríquez (UCSH), Santiago de Chile.

[http://ediciones.ucsh.cl/ojs/index.php/RHyG/article/view/1694/1556] 